\title{
Exploring an approach based on digital games for teaching programming concepts to young children
}

\author{
Tancicleide C. S. Gomes \\ Universidade Federal de \\ Pernambuco \\ Recife, Brasil \\ tancicleide.gomes@gmail.com
}

\author{
Taciana Pontual da Rocha \\ Falcão \\ Universidade Federal Rural de \\ Pernambuco \\ Recife, Brasil \\ taciana.pontual@gmail.com
}

\author{
Patricia C. A. Restelli Tedesco \\ Universidade Federal de \\ Pernambuco \\ Recife, Brasil \\ pcart@cin.ufpe.br
}

\begin{abstract}
RESUMO
Notadamente, as discussões relacionadas ao ensino de programação para crianças não são recentes e por este motivo existe uma ampla gama de recursos relacionados, como: brinquedos programáveis, brinquedos híbridos, jogos digitais, atividades com materiais analógicos, entre outros. $\mathrm{O}$ presente trabalho relata uma experiência baseada em jogos digitais para o ensino de conceitos de programação para crianças pequenas em fase de letramento. Nosso principal objetivo consistiu em investigar como alguns conceitos são apresentados na interface de alguns jogos e qual o impacto dos elementos de interação na compreensão das crianças sobre os conceitos apresentados. Os resultados demonstraram uma compreensão adequada de sequências de instruções e condicionais, mas indicam alguns desafios no que se refere sobretudo aos textos e elementos de interação, assim como símbolos gráficos. Outro ponto importante diz respeito ao conceito de repetição, considerado particularmente difícil de compreender pelas crianças. Sendo assim, compreendemos que embora existam diversos recursos voltados ao ensino de programação para crianças, ainda não temos boas soluções para representar e abordar alguns conceitos para crianças em fase de letramento.
\end{abstract}

\section{Palavras-chave}

jogos digitais, crianças pequenas, programação, interação criança-jogo

\section{ACM Classification Keywords}

H.5.m. Information interfaces and presentation

\section{INTRODUÇÃO}

Muito embora algumas pesquisas demonstrem que o envolvimento das crianças em experiências de aprendizado de programação as auxilie a desenvolver habilidades de linguagem e numeracia [1], ainda existem questões sobre o

Permission to make digital or hard copies of all or part of this work for personal or classroom use is granted without fee provided that copies are not made or distributed for profit or commercial advantage and that copies bear this notice and the full citation on the first page. Copyrights for components of this work owned by others than the author(s) must be honored. Abstracting with credit is permitted. To copy otherwise, or republish, to post on servers or to redistribute to lists, requires prior specific permission and/or a fee. Copyright 2018 SBC.

IHC 2018, Anais Estendidos do XVII Simpósio Brasileiro sobre Fatores Humanos em Sistemas Computacionais

Outubro 22-26, 2018, Belém, Brasil

Artigos Internacionais ensino de Ciência da Computação, sobretudo quando se trata de crianças pequenas. Segundo Wing [2], a disseminação do pensamento computacional especialmente para crianças, envolve muitos desafios, como as formas efetivas de aprender (ensinar) por (para) crianças; e as melhores formas de integrar as diversas ferramentas disponíveis neste processo. Ainda não há consenso sobre como abordar o pensamento computacional com crianças nem sobre quais tópicos devem ser abordados.

Mediante este contexto, neste trabalho estivemos especialmente interessadas em compreender como jogos digitais apresentam conceitos de programação em sua interface e como os elementos de interação interferem na compreensão destes conceitos pelas crianças em fase de letramento. Este trabalho pode ser interessante para pesquisadores, educadores, designers e desenvolvedores de jogos que estejam interessados em projetar jogos digitais ou experiências baseadas em jogos para crianças pequenas em fase de letramento.

\section{DESIGN DO ESTUDO}

O presente trabalho relata os resultados iniciais de uma pesquisa-ação educacional que visa aprimorar o ensino de conceitos de programação para crianças pequenas por meio de jogos digitais. Este trabalho, em particular, busca compreender como os conceitos de programação são veiculados através dos elementos de interação da interface dos jogos e como esses elementos contribuem para a compreensão das crianças. Este trabalho integrou uma disciplina de Informática, lecionada em uma escola tradicional de Educação Infantil da rede particular em Recife, Pernambuco, em que participaram 42 alunos com idades entre 5 e 7 anos.

Essas aulas eram ministradas como atividades extracurriculares e ocorriam na sala de Informática da escola, com dez computadores desktop conectados à Internet. Na falta de uma definição de competências, habilidades e conteúdos para a disciplina em questão, a professorapesquisadora propôs a introdução de conceitos relacionados ao pensamento computacional. Em razão de não haver um currículo nacional abrangendo Ciência da Computação em nível escolar, optamos pelo currículo Computing at School [3]. Os jogos digitais envolvendo os conceitos a serem abordados foram utilizados como ferramentas de ensino. 
Em cada aula, as crianças eram convidadas a jogar um jogo específico sem nenhuma explicação prévia sobre o conteúdo ou instruções sobre como jogar. Eles poderiam pedir a ajuda da professora ou de seus colegas a qualquer momento. Após a interação, e nas aulas subsequentes, os conceitos envolvidos nos jogos foram mais explorados pelo professor, esclarecendo as relações entre os conceitos e as situações apresentadas nos jogos. Por exemplo, a professor perguntou se os alunos notaram diferenças no comportamento dos personagens quando a ordem das instruções foi modificada, ou uma instrução específica foi substituída por outra, com o objetivo de melhorar a compreensão dos alunos sobre a sequência de instruções em um algoritmo (embora tal terminologia formal não tenha sido adotada neste ponto).

\section{RESULTADOS, DISCUSSÕES E CONSIDERAÇÕES FINAIS}

Os resultados apontam uma ampla gama de desafios e oportunidades de pesquisa. Uma das principais contribuições consiste em servir como um ponto de partida para os professores interessados em ensinar conceitos de programação para crianças pequenas a partir de jogos digitais, assim como uma fonte de ideias e desafios de design para as diversas comunidades envolvidas no projeto e desenvolvimento desses jogos.

Entre os desafios encontrados, realçamos a complexidade da linguagem (visual e textual). Encontramos tutoriais, sistemas de ajuda e feedback com construções textuais complexas em alguns dos jogos escolhidos (ex. Code Baymax, LightBot), mesmo tendo sido projetados para crianças nesta faixa etária. Este aspecto é especialmente relevante porque as crianças pequenas ainda estão aprendendo a ler e tendem a ignorar tutoriais e textos de ajuda, mas prestam atenção à cinemáticas animadas ou interativas. A linguagem visual adotada, por sua vez, demonstrou que aparentemente ainda não encontramos maneiras adequadas de representarmos (ex. símbolos ou abordagens) alguns conceitos para crianças pequenas. Não consideramos que exista um consenso sobre quais conteúdos de programação deveriam ser ensinados e quais deles são compreendidos adequadamente por crianças nesta idade, e muitos currículos apenas apontam para o desenvolvimento do pensamento algorítmico.

Entre os três conceitos de programação abordados (sequenciamento de instruções, condicionais e repetição), a repetição tem se mostrado de difícil entendimento para as crianças. Para ajudar as crianças a compreenderem melhor este conceito combinamos atividades de sala de aula, exercícios extras e jogos físicos. Notadamente, estes resultados são consoantes aos trabalhos relacionados (inserir referências), que indicam a necessidade de atividades complementares e o apoio significativo do professor para ajudar a compreensão das crianças sobre conceitos, principalmente repetição e giros à direita / esquerda. Isso mostra que, apesar do crescente número de jogos digitais para programação sendo lançados, boas soluções para transmitir os principais conceitos para crianças pequenas ainda não foram encontrados.

Em suma, a partir dos resultados obtidos neste estudo desenvolvido em sala de aula compreendemos que uma abordagem para crianças pequenas que seja exclusivamente baseado em versões gratuitas de jogos digitais pode não ser suficientemente adequada para apresentar e explorar os conceitos de programação propostos. Mediante este contexto, deixamos as seguintes recomendações para os interessados em utilizarem jogos para abordar conceitos de programação com crianças desta faixa etária: (a) combinem diferentes maneiras de representar os conceitos (particularmente para os mais abstratos), por exemplo, combinar jogos digitais que usam diferentes representações de um mesmo conceito ou combinar jogos digitais com abordagens como jogos físicos, tarefas em papel, brinquedos e outras atividades lúdicas); (b) priorizar jogos que envolvam narrativas e linguagens visuais; e (c) explorar possibilidades de contar histórias para apresentar os conceitos usando narrativas que se conectam ao contexto das crianças. De um modo geral, os jogos analisados compartilham limitações semelhantes quanto às particularidades do uso formal nas escolas.

\section{REFERÊNCIAS}

1. D.H. Clements, J. Sarama, Teaching with computers in early childhood education: Strategies and professional development, Journal of Early Childhood Teacher Education, 23-3 (2010) 215226.

2. J. M. Wing, Computational Thinking, Communications of the ACM, 49-3 (2006) 33-35.

3. Computer Science: A curriculum for schools, Computing at School Working Group. http://bit.ly/1MNe9Mi, 2012. 